\title{
Integration of professional and ecological education students of civil engineering institute: problems and prospects
}

\author{
Sofia A. Mudrak ${ }^{*}$ \\ Moscow State University of Civil Engineering, Yaroslavskoe shosse, 26, Moscow, 129337, Russia
}

\begin{abstract}
This article analyzes the problems associated with the ecologization of engineering education. Ecological competence is considered as an integral feature of ecological-oriented personality with ecological focused consciousness. According to the author, prospects for the development of ecological component in engineering education related with the introduction of an integrative approach. Singles out the main levels and directions of integration of professional and ecological education in the engineering institute. This article gives the data of empirical research of ecological consciousness of students - the future engineers. It gives the conclusion about the need of special educational activities for the formation of ecocentric environmental consciousness of students, taking into account the specifics of professional education.
\end{abstract}

\section{Introduction}

The concept of long-term socio-economic development of the Russian Federation for the period up to 2020 set a strategic goal is to prepare specialists who will be able to realize the ecological priorities of the state policy in the professional activity.

Ecological condition of Russia at the current stage is characterized as critical. There is a contradiction between the needs of society and production of ecologically qualified specialists, who have to make professional decisions with environmental and economic consequences, and insufficient of theoretical and practical state of the domestic environmental education, the level of its development in university.

Focusing on preparation of "pure ecologist" does not solve this problem. Every industry sector has its own features of interaction with the environment and their directions of ecological approach. Therefore we need specialists with deep professional knowledge and at the same time who will be able to realize an ecologically oriented approach and environmentally friendly technologies in their professional activities.

The specificity of professional activity of the engineer is the creation of objects. But their construction is done by deep intervention into the nature. Therefore, the future experts of construction are necessary to have an idea of the nature and rules of human interaction

*Corresponding author: avelis@bk.ru 
with the environment, have the willingness and ability to solve environmental issues, experience in practical affairs to preserve and improve the environment, environmentally significant personal qualities, i.e. to be environmentally qualified[1,2]. It becomes relevant introduction of integrative professional and ecological education in the process of training students in the university.

Ecological competence is considered by us as a complex personality formation. This is a required component of an immanent sign of high level of professionalism of the future expert, regardless of professional activity (S. A. Mudrak, A. V. Gagarin).

This is how we define environmental competence of the person. This is integrative and over professional characteristic of the person. It reflects a willingness and ability to act from a position of environmental viability in professional and other spheres of life, possessing a wide range of environmental, scientific, legal knowledge, a sense of unity and understanding the depth of the relationship of all living things, based on ecological oriented motivation, environmentally significant qualities of the person and ecology focused consciousness [3].

Essential features of ecological competence of the person we define as: integrative, over professional characteristic, high social importance, the presence of ecologically significant qualities of the person in the structure (humanity, responsibility, empathy, thrift, and others.), acmeological component (an invariant of professionalism), axiological component (carries ethically-meaning), including representations of nature as an essential value, predictability (involved long term perspective), the impact on subject characteristics (expands the spatial and temporal components), initially conflict (internal struggle to overcome anthropocentrism and egocentrism) [4].

Environmental awareness is a broader concept than ecological competence. A person with a high level of ecological competence has ecocentric environmental consciousness, and at a low level is determined as anthropocentric type of ecological consciousness. On this basis, ecocentric type of ecological consciousness can be an important diagnostic criterion of ecological competence of the person and the purpose of professional education of any orientation [5].

In modern educational research integration acts as a major methodological category, because it is aimed at ensuring the continuity of the educational process (Y.M. Grishaeva, M.A. Kartavykh, M.A. Povalyaeva, A.A. Salamatov et al.).

Integration means the original unity of disciplinary and inter-disciplinary. This is not just a mechanical connection of different knowledge, but the usage of the approach, in which they are interrelated, as a result in solving certain problems people, can act systematically. Integration in education is a mechanism that is aimed at developing a systematic and creative thinking.

The main directions of integration processes in education, in terms of the V.N. Maximova, considered from two perspectives: first, education is a result of integrative trends in the development of science andculture as a whole, unified picture of the world in order to create a holistic system of knowledge of the young generation. Second, the education is an integrative field of human activity, the subject of which is the development of the growing human in the system of connections and relationships with the world.

The first position is reflected in the content of the educational process, and the second relates largely to its technological content, when integration is reduced to the interaction of different types of activities

There are several stages of integration that are horizontally combined into larger bases (M. A. Povalyaeva):

Subject integration. In this case, two or three academic discipline are committed to explain one topic. 
Problem integration. In this case, the integration means that one problem is involved in different discipline.

Conceptual integration. In this case it meant that the review is carried out in several subjects with all their methods and means.

Theoretical integration. In this case it's considered as interpenetration of different theories.

Dialectical integration. In this case, the integration is understood as the usage of the principles and concepts that relate to different areas of knowledge. As an alternative explanation you can find: the interpretation of the world as a holistic picture. It purports to eventually form the ideological system.

In the context of the modernization of the current professional-ecological education integration processes of it take particular importance. The obvious value of this pedagogical phenomenon is to unite in "the objective integrity of the system from the various levels (nature - society - people)". Integration in education - is not a fashion but a necessity to prepare qualified specialists for all kinds of human activity. We introduced the concept of "engineering ecology». It is presented as a science, which will contribute to "the development of new way of thinking in engineering, new environmental" psychology "in the modern developing world" (A.D. Potapov, V. I. Tomacov et al.).

\section{Tasks and results}

The aim of the innovation integrative professional-ecological approach is not simply a transfer of additional knowledge and skills to students, but also the formation of the overall environmental professional competence of the future specialists, which is reflected in the formation of environmentally significant qualities of personality and ecologically oriented (ecocentric) consciousness [6]. This changes the attitude to nature and makes any activity considered from the point of view of environmental viability [7].

Technologies, including environmental, in the modern world becomes quite quickly outdated. Only a person possessing an ecologically oriented consciousness is able to search and quickly find new approaches to solve specific environmental problems. In this way ecocentric environmental awareness became the main result of well-formed environmental education and guarantor of greening activities. In the works of leading ecopsychology V.I. Panov notes that modern man requires ecological reorientation of professional, personal and social consciousness at the current stage. Development of an integrative professionalecological approach in the education in the engineering university will help to better understand the structure of ecological consciousness, psychological and pedagogical specifics of its formation, and the relationship with environmental competence of the individual. In 2016, we conducted a pilot empirical research of features of environmental consciousness and attitude towards environmental problems in the engineering university.

The empirical base of research The research involved undergraduate students NRU MSUCE. It's include 50 participants, equalized the sample by gender and age.

\subsection{Research methods}

We have used a special ecological profile, modified by M. Rokeach method of determining the value orientations, TEM technique.

\subsection{Results}

\subsubsection{Results of questioning}


Most of the students have confirmed their interest in environmental issues.52\% of respondents chose an affirmative answer "yes, actively interested in this."The main sources of information for students (68\%) were television and radio.

The vast majority of students are aware of the existence of the global environmental crisis, $43 \%$ of them believe that the pollution of the human environment is a major cause of the ecological crisis. According to students, the solution of environmental problems in our country depends on the society itself $(75 \%)$.

The foreign experience in the development of environmental management in relation to Russia is very cautious. Firstly, students with it "unfamiliar" or "do not know" " $(60 \%)$.Secondly, it is believed that it may be applied to a small extent with restrictions $(73 \%)$.

Students correctly assess the role of environmental education as an important component of environmental awareness and ecological culture of the person. The most significant elements of ecological culture they considered: ecological knowledge $(65 \%)$, environmental liability (63\%), ecological oriented activities (45\%), personal experience with nature $(43 \%)$.

According to respondents, the main contributes to formation of ecological culture is kind of activity as environmental education(70\%). The most effective in modern conditions are considered (78\%), traditional forms of obtaining professional environmental knowledge: internships, training, ecological courses in universities. At the same time, students noted that it is necessary to strengthen the link environmental education with practical activities $(60 \%)$ pay more attention to the organization of training $(53 \%)$, deep knowledge of modern environmental technology (40\%).

\subsubsection{The results of the study by the method of $M$. Rokeach value orientations in modification by V.V. Kalita}

The findings suggest that for future engineers the most important is individual success associated with study and work, as well as the success a small group. Students are characterized by high value of education. This is due to the fact that the dominant activity at the moment for all subjects is university studies, for special professional knowledge and skills, which largely determine their future. Students are also characterized by high levels of preference values that are important for communication.

On average environmental values are at very low rating for the students. Apparently, they suggest that such course of action and the organization does not contribute to the solution of their main goals. It also should be noticed that in rating of value orientations in general, in particular the ecological, most important are the individual differences, especially when it comes to values that are not so much rooted in the public consciousness, such as "health".

\subsubsection{The results for TEM method}

In the analysis of the results from the four scales of subtest "Environmental threats" 30 students are determined by the type of ecocentric environmental awareness $(60 \%$ of the respondents), 20 persons are determined by type of the anthropocentric environmental awareness ( $40 \%$ of the respondents).

In environmental consciousness of students the positive impact of nature (39.8) on society is estimated as more superior than the possible adverse effects associated with nature (34).These results point to the sufficient level of cognitive component of environmental awareness among students, as well as a trend towards to a positive perception of the system "man - environment». In addition, there is a high level of 
understanding of the negative human impact on nature (49.8), a positive human impact on the environment is assessed as a much smaller (34.1).

The ecological consciousness of students - the future engineers is characterized by a medium level of development of the cognitive component. Motivation to ecology oriented activities and ecological self-education is fragile. Environmental values do not have priority. The emotional aspect is characterized moderate feeling of unity with nature, some decrease in the role of aesthetic sensations, the presence of anxiety and concern about the possible consequences of the ecological crisis. The reflective component includes the awareness of the existence of the ecological crisis, the low level of assessment of their environmental knowledge and environmental culture in general pessimism towards the possibility of effective solutions to environmental problems.

These results demonstrate the need to implement special educational activities in the university to form ecocentric environmental consciousness among the students.

Based on the analysis of theoretical data sources and empirical research, we reveal the main problems of greening the engineering education:

1. The traditional separation of professional (including engineering) and environmental education.

2. Consideration of ecological competence as a narrow professional rather than general (integrated).

3. Practically complete absence of disciplines that related to environmental issues, in engineering university.

4. Separation of environmental upbringing and environmental education in university.

5. Insufficient request by the employer and students on the greening of professional training. At a time when there is a request from the state and part of the pedagogical community.

6. Priority to predict the consequences of their professional activities for technogenic and society environments (if necessary to predict their simultaneously for technogenic, society environments and nature). "The life cycle" of the construction object is practically not correlated from surrounding natural environment. .

Prospects of the development professional and ecological education of the future engineers, in our opinion, related to the implementation of the integrative approach, which is determined by the following points:

1. Consideration greening of professional education as a socio-cultural phenomenon and as inevitability for post-industrial society.

2. Modernization of psycho-pedagogical techniques of environmental education of engineering students on the basis of competence approach with considering the increasing role of self-study [8].

3. The inclusion of environmental competence to the general cultural competence, as a state request and the recognition of its importance, regardless from professional activities.

4. Introduction of new methods for forming professional-ecological competence (environmental game, solving environmental problems and case studies, design from ecological position).

5. Comprehensive educational impact on the student's personality. Inclusion the elements of environmental education to form environmentally significant personality traits and environmentally conscious consciousness.

6. The introduction of all levels of educational integration (from the thematic to the dialectical stage) in education process. 
7. Development of social conditions, psychological and pedagogical mechanism, legal framework for the formation of ecological competence of the engineering students.

8. Integration of various specialists: engineers, ecologists, psychologists, sociologists, lawyers in the educational process at the university for forming students with environmental competence.

\section{Conclusions}

The following aspects lead to problems of greening education in construction industry: consideration of ecological competence as a narrow professional rather than general; the traditional separation of professional and environmental education; practically absence of disciplines that related to environmental issues; the separation of environmental upbringing and environmental education in the university; no request from employers and students on greening professional education; priority to predict the consequences of their professional activities for technogenic and society environments excluding nature.

The aim of the innovation integrative professional-ecological approach is not merely a transfer of additional knowledge and skills of students, but also the formation of ecological competence of future specialist, which is reflected in the formation of environmentally significant qualities of personality and ecologically oriented (ecocentric) consciousness.

Conducted empirical research indicates the need for special educational and upbringing activities at the university to form ecologically oriented consciousness of the future engineers.

Prospects for the development of vocational and environmental education of the future engineers associated with the implementation of the integrative approach, which is determined by the modernization of psychological and pedagogical technologies of ecological education of students on the basis of competence-based approach; the inclusion of environmental competence to the general cultural competence; introduction of new methods (environmental game, dealing with environmental cases and etc.); inclusion the elements of environmental education to form environmentally significant personality traits and environmentally conscious consciousness; using all levels of pedagogical integration in the educational process; integration of various specialists in the educational process at the university for forming students with environmental competence integration in the educational process, the integration of various specialists in the educational space of the university for the formation of ecological competence of students.

\section{References}

1. E. Romanova, MATEC, 73, 07010 (2016)

2. E. Khripko, MATEC, 73, 07021 (2016)

3. S.A. Mudrak, A.V. Gagarin, V.V. Glebov, Vestnik Rossijskogo universiteta družby narodov. Seriâ Psihologiâ i pedagogika, Russia, 28/4, 78-84 (2012)

4. S.A. Mudrak, SGEM Conference Proceedings, 1, 131-138 (2016)

5. M.G. Leontev, MATEC, 73, 07005 (2016)

6. E.A. Shnyrenkov, I.P. Pryadko, Procedia Engineering, 117, 325-330 (2015)

7. Z. Ivanova, O. Yudenkova, International Education Studies, 8/5, 232-239 (2015)

8. A.D. Ishkov, N.G. Miloradova, A.Yu. Chernyshev, Procedia - Social and Behavioral Sciences, 171, 765-770 (2015) 